\title{
Viscoelasticity of crystal- and bubble-bearing rhyolite melts
}

\author{
N.S. Bagdassarov *, D.B. Dingwell, S.L. Webb \\ Bayerisches Geoinstitut, Universität Bayreuth, D-95440 Bayreuth, Germany
}

(Received 9 September 1993; revision accepted 21 January 1994)

\begin{abstract}
The effect of non-deformable inclusions on the frequency-dependent rheology of a rhyolite melt plus crystals has been investigated using a sinusoidal torsion deformation device for measurements of shear viscosity and modulus in the frequency range of $5 \mathrm{mHz}$ to $20 \mathrm{~Hz}$ at temperatures of $750-1050^{\circ} \mathrm{C}$. The relaxed shear viscosity and unrelaxed shear modulus of rhyolite magma (rhyolite melt plus crystals plus bubbles) decreases with increasing bubble content and increases with the addition of crystals. At a crystal concentration of about $45 \%$ a relaxed value of the shear viscosity is not attainable. The presence of rigid inclusions results in an imaginary component of the shear modulus that becomes more symmetrical and shifted to the low-frequency-high-temperature range with respect to that for a crystal-free melt. The slope of $\log \left(Q^{-1}\right)$ (internal friction) as a function of the dimensionless variable $\log (\omega \tau)$, is unaffected in the low-temperature-high-frequency range of crystals, with $Q^{-1} \approx 1 /(\omega \tau)^{0.5}$ (the same as for bubbleand crystal-free rhyolite). For the present type of suspension, the internal friction is practically constant and independent of $\log (\omega \tau)$ in the high-temperature-low-frequency limit $(\omega \tau \ll 1)$. The shape of the Cole-Cole diagram becomes symmetrical and can be described as a Caputo body with parameter $\gamma \approx 0.45$, whereas for bubble-bearing and inclusion-free rhyolite melts the shape of diagram relates to the $\beta$-relaxation exponent with $\beta \approx 0.5$. The present work demonstrates that magma may or may not follow a power-law rheology depending on the relative volume proportion between crystals and bubbles.
\end{abstract}

\section{Introduction}

The purpose of this study is to evaluate the role of rigid inclusions or crystals on the shear deformation of rhyolite melt at varying strainrates and temperatures. Interest in the frequency-dependent rheology of multi-phase magmatic systems stems from the non-Newtonian behavior of such systems (i.e. their strong strain-de-

\footnotetext{
* Corresponding author.
}

pendent and/or strain-rate-dependent rheology). Strain-rate-dependent rheology of partially molten rock and concentrated suspensions can result from the flow of melt within the intergranular spaces of the crystalline matrix and/or from viscoelastic behavior of the melt itself. With the addition of rigid inclusions to a viscous melt, one might expect, at a certain fraction of crystals (the rheologically critical melt percentage), a transition in rheology from viscoelastic behavior of the dilute suspension to power-law creep rheology of a concentrated suspension, dependent on crystal-crystal interactions. At high concentrations of 
rigid particles dispersed in a viscoelastic melt, the observed viscoelastic response of these suspensions has a markedly non-linear strain-rate-dependent character even under conditions of a linear viscoelastic response of the host melt (Nguyen and Boger, 1992). The response of highly viscous concentrated magmatic suspensions to small strains in dynamic testing provides important information on the rheological behavior of magmas under controlled conditions. This information is a prerequisite for the understanding of magma behavior under the widely varying conditions of strain and strain-rate in nature (Dingwell et al., 1993). For the prediction of magma flow rates, it is important to know their mechanical response measured experimentally as a function of strain-rate (or frequency). The experimental method employed here to study the viscoelastic behavior of synthetic suspensions of rhyolite melt and crystals is that of oscillatory shear (provided by torsional deformation) of cylindrical samples. This dynamic method has been described and previously employed for the anelasticity and the viscoelasticity studies of partially melted rocks (Berckhemer et al., 1982), rhyolite melt (Webb, 1992) and vesicular rhyolite melt (Bagdassarov and Dingwell, 1993a).

\subsection{Multi-phase rheology of composite materials}

Systematic investigations of the rheological properties of magmatic suspensions have begun relatively recently. These studies have dealt with suspensions of melt and vesicles in the following conditions: (1) at melt viscosity of $10^{5} \mathrm{~Pa}$ s, using a rotational viscometer (Stein and Spera, 1992); (2) in the viscosity range $10^{10}-10^{11} \mathrm{~Pa} \mathrm{~s}$, using a longitudinal deformation viscometer (Bagdassarov and Dingwell, 1992); (3) in the viscosity range $10^{9}-10^{11} \mathrm{~Pa} \mathrm{~s}$, using an oscillatory torsional shear deformation (Bagdassarov and Dingwell, 1993a). Additionally, magmatic suspensions consisting of melt and crystals at viscosities of $10^{1}$ $10^{3} \mathrm{~Pa} s$ have been studied using rotational viscometry (Ryerson et al., 1988).

The synthetic suspensions considered in this study consist of rhyolite melt and spherical crystalline inclusions $\left(\mathrm{Al}_{2} \mathrm{O}_{3}\right)$ with or without bubbles in the viscosity range $10^{8}-10^{11} \mathrm{~Pa}$. The presence of deformable and rigid heterogeneities changes the shear modulus and viscosity of a multi-phase material. If the cavities are rigid (inviscid) inclusions then the unrelaxed shear modulus of the suspension $(\bar{G})$ increases with the volume percentage of inclusions $(\phi)$

$\bar{G} \approx G[1+(5 / 2) \phi+\ldots]$

(see Chen and Acrivos, 1978). The relative value of the relaxed shear viscosity $\left(\eta_{\mathrm{r}}\right)$ increases with the increasing ratio of the volume percentage of rigid inclusions $(\phi)$ to the critical fraction of them $\left(\phi_{\mathrm{cr}}\right)$ as

$\eta_{\mathrm{r}}=\left(1-\phi / \phi_{\mathrm{cr}}\right)^{-2.5}$

which is valid for concentrations of inclusions less than $30 \%$ (Roscoe, 1952). The presence of rigid inclusions in the liquid also eventually results in a yield stress (Nguyen and Boger, 1992) which can be explained in terms of particle-particle interactions leading to the formation of a network structure in concentrated suspensions. This has been observed in dynamic experiments on complex shear viscosity and modulus in various industrial synthetic suspensions (e.g. Michaels and Bolger, 1962), and in rotational viscometry experiments on magmatic melts (Ryerson et al., 1988). Experimental rheological studies of industrial suspensions have partially confirmed the Roscoe model (Roscoe, 1953), in which the resistance to creep of a concentrated suspension at low strain-rate is due to a 'structural viscosity' representing the strength at which the network of particles can be broken plus a viscous resistance of the liquid itself. Thus, the yield strength of a concentrated suspension is a shear strength of a network. At high strain-rates this value is much less than the unrelaxed shear modulus of the liquid $G_{\infty}$, and is practically unobservable. At low strain-rates this value determines the macroscopic yield strength of the composite flow. In the low-frequencyhigh-temperature range the composite material consisting of a viscoelastic melt and rigid inclusions will have a much longer relaxation time than the longest relaxation time of the viscoelastic liquid itself (see Nguyen and Boger, 1992). At low shear-rates when the behavior of the inter- 
granular liquid is purely viscous, suspended particles begin to interact mechanically and form a network that is responsible for the small elastic component of the mechanical response (Matsumoto et al., 1973). Experimental studies with carbon black in polystyrene solutions (Onogi et al., 1970), flocculated kaolin suspension (Michaels and Bolger, 1962), and magnetic and non-magnetic particles in mineral oil (Kanai et al., 1992) have demonstrated a critical volume fraction of suspended particles below which the suspension does not show yield stress and possesses a relaxed shear viscosity. Above this critical concentration a non-zero relaxed shear modulus appears,

$$
G_{0}^{*}(\omega \rightarrow 0)=\left[\left(G_{0}^{\prime}\right)^{2}+\left(G_{0}^{\prime \prime}\right)^{2}\right]^{\frac{2}{2}} \approx\left(\phi-\phi_{\mathrm{cr}}\right)^{n}
$$

where $G_{0}^{*}$ is the complex shear modulus, $G_{0}^{\prime}$ and $G_{0}^{\prime \prime}$ are respectively the real and imaginary parts of the complex shear modulus at low frequencies, $\phi$ is the volume concentration of suspended particles, $\phi_{\mathrm{cr}}$ is the critical concentration of particles and $n$ is an empirical constant (e.g. Nguyen and Boger, 1992; Kanai et al., 1992). The parameter $n=3$ has been estimated in experiments on flocculated kaolin suspension (Michaels and Bolger, 1962), and $n=2$ has been observed for colloidal suspensions (Zosel, 1982). For concentrations of heterogeneities close to critical a relaxed Newto- nian shear viscosity is not observed; rather the rheological behavior is strain-rate dependent (power-law creep).

In magma rheology this transition from one type of behavior to another relates to the 'rheologically critical' percentage of melt (Arzi, 1978). This value distinguishes the flow of magma and lavas in which the concentration of crystals is sub-critical, and the creep rheology of partially molten rocks containing low melt fractions (see Dingwell et al., 1993). The present work demonstrates the onset of transition behavior from viscous magma flow to creep of partially molten rocks for a magmatic suspension consisting of rhyolite melt charged with spherical crystal inclusions.

\section{Experimental procedure}

Little Glass Mountain obsidian (California; denoted LGM) was chosen as starting material for the preparation of samples with differing concentrations of crystals. The chemical composition of LGM rhyolite is given in Table 1. A crystal- and bubble-free glass of rhyolite was obtained by stirring the melted obsidian at $1650^{\circ} \mathrm{C}$ for 7 days. Chips of rhyolite glass were ground into a fine powder (grain size $5-10 \mu \mathrm{m}$ ) and mixed with sapphire spheres $(0.5 \mathrm{~mm}$ in diameter, C. Giese

Table 1

Chemical composition of samples (values for the mixtures are for various distances from the edge of a sapphire sphere)

\begin{tabular}{|c|c|c|c|c|c|c|c|c|c|c|}
\hline \multirow[t]{2}{*}{ Oxide } & \multirow{2}{*}{$\begin{array}{l}\text { LGM } \\
\text { (initial }_{\text {composition) }}^{a}\end{array}$} & \multicolumn{3}{|c|}{$\begin{array}{l}\text { LGM } \\
(9 \% \text { porosity }+9 \% \text { crystals })^{b}\end{array}$} & \multicolumn{3}{|c|}{$\begin{array}{l}\text { LGM } \\
(16 \% \text { porosity }+16 \% \text { crystals })^{b}\end{array}$} & \multicolumn{3}{|c|}{$\begin{array}{l}\text { LGM } \\
(40 \% \text { porosity }+40 \% \text { crystals })\end{array}$} \\
\hline & & $5 \mu \mathrm{m}$ & $20 \mu \mathrm{m}$ & $80 \mu \mathrm{m}$ & $5 \mu \mathrm{m}$ & $20 \mu \mathrm{m}$ & $80 \mu \mathrm{m}$ & $5 \mu \mathrm{m}$ & $20 \mu \mathrm{m}$ & $80 \mu \mathrm{m}$ \\
\hline $\mathrm{SiO}_{2}$ & 74.75 & 71.66 & 74.98 & 75.07 & 72.06 & 75.07 & 74.83 & 73.37 & 75.01 & 75.08 \\
\hline $\mathrm{TiO}_{2}$ & 0.29 & 0.38 & 0.24 & 0.30 & 0.34 & 0.30 & 0.15 & 0.30 & 0.41 & 0.26 \\
\hline $\mathrm{Al}_{2} \mathrm{O}_{3}$ & 13.30 & 15.08 & 13.61 & 13.42 & 15.71 & 13.27 & 13.16 & 14.67 & 13.22 & 13.11 \\
\hline $\mathrm{FeO}^{\circ}$ & 1.86 & 1.72 & 1.61 & 2.06 & 1.31 & 1.86 & 1.85 & 1.47 & 2.02 & 1.91 \\
\hline $\mathrm{MgO}$ & 0.29 & 0.41 & 0.27 & 0.27 & 0.41 & 0.23 & 0.27 & 0.27 & 0.25 & 0.28 \\
\hline $\mathrm{CaO}$ & 1.21 & 1.80 & 1.01 & 0.89 & 1.86 & 0.92 & 1.09 & 1.18 & 0.96 & 1.06 \\
\hline $\mathrm{Na}_{2} \mathrm{O}$ & 4.51 & 5.45 & 4.12 & 4.05 & 5.05 & 4.18 & 4.11 & 4.73 & 4.29 & 4.31 \\
\hline $\mathrm{K}_{2} \mathrm{O}$ & 3.86 & 3.90 & 3.78 & 3.72 & 3.92 & 3.89 & 3.81 & 4.01 & 3.82 & 3.87 \\
\hline
\end{tabular}

a Determined by inductively coupled plasma atomic emission spectrometry (ICP-AES) in weight per cent, using single element solution standards.

${ }^{b}$ Determined by Camebax microprobe, at $15 \mathrm{kV}, 15 \mathrm{nA}$, beam spot is $2 \mu \mathrm{m}$.

${ }^{c} \mathrm{FeO}$ is taken as the sum of ferric and ferrous iron. 


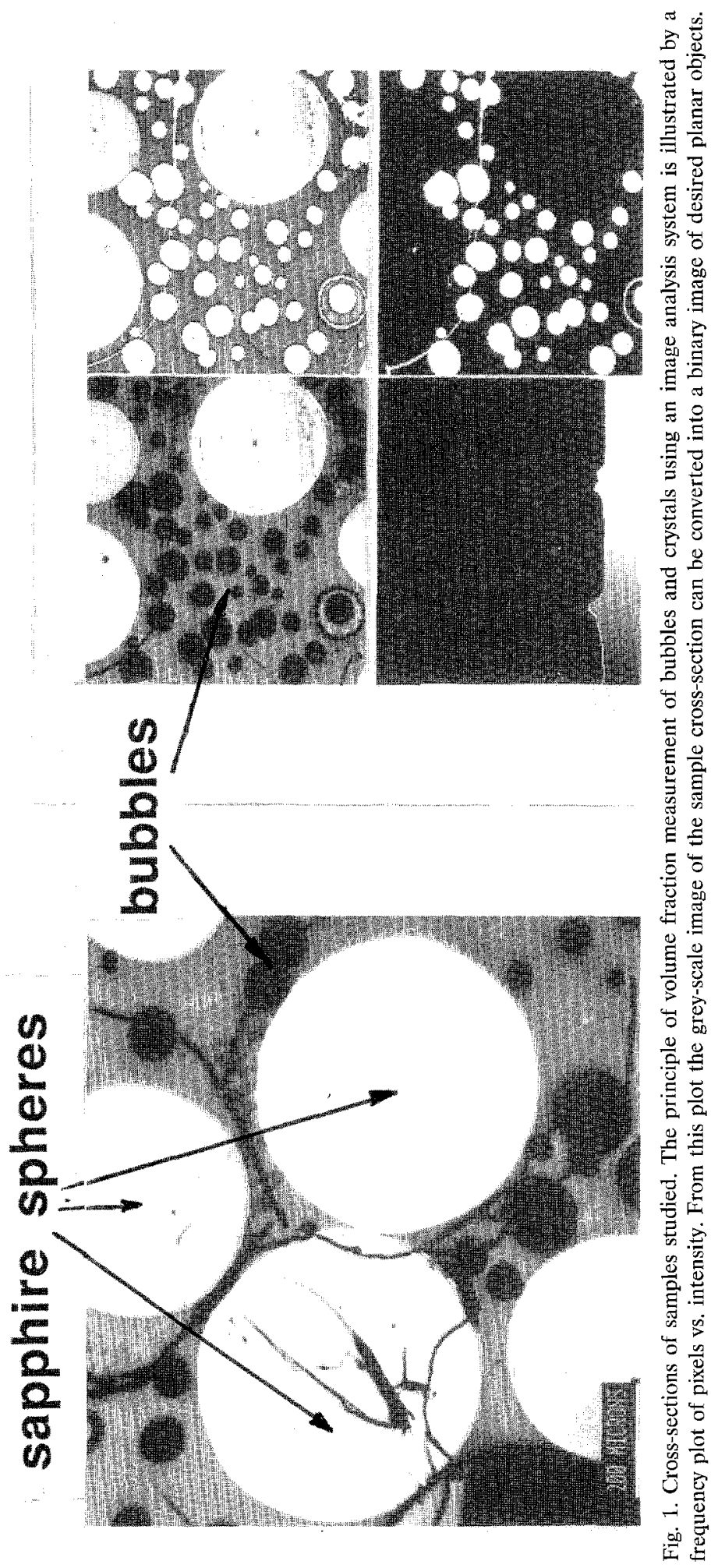


$\mathrm{KG}^{\circledR}$, Idar-Oberstein, Germany) in the desired proportions. Mixtures were homogenized by agitation in plastic bottles. Samples $(8 \mathrm{~mm}$ in diameter and $25-30 \mathrm{~mm}$ in length) were pressed in a cylindrical pressing form at room temperature. The pressed cylinders were coated with $\mathrm{Pt}$ foil tubes, placed between alumina rods and melted by application of a small axial load (see also

Real Component of Shear Viscosity LGM: $82 \%$ melt $+9 \%$ bubbles $+9 \%$ sapphire spheres

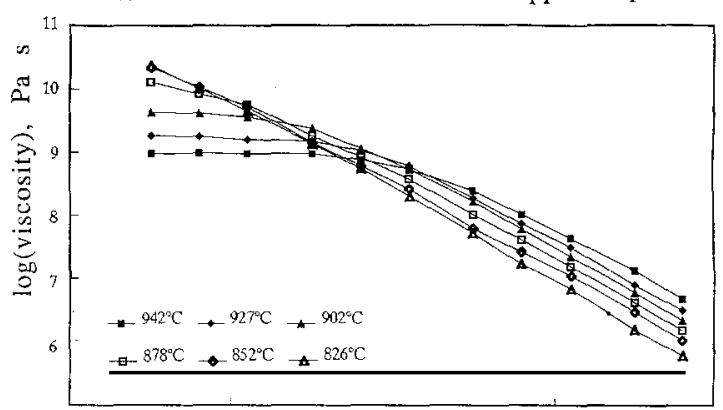

LGM: $68 \%$ melt $+16 \%$ bubbles $+16 \%$ sapphire spheres

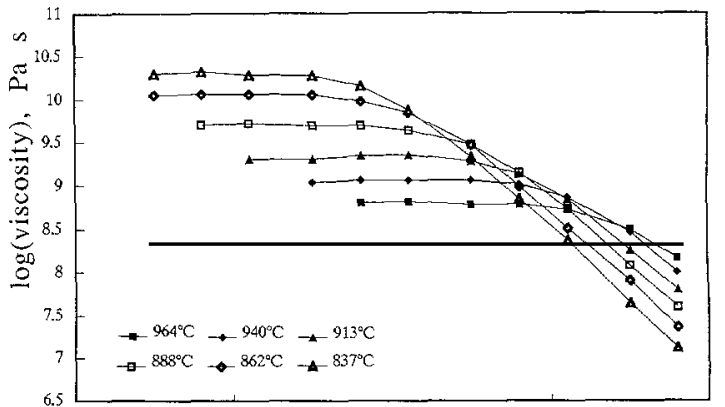

LGM: $20 \%$ melt $+40 \%$ bubbles $+40 \%$ sapphire sphere

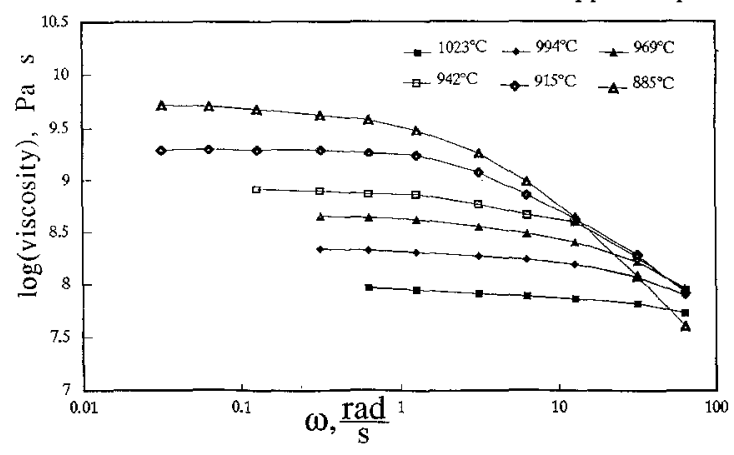

Bagdassarov and Dingwell, 1993a). Samples were sintered for $6-10 \mathrm{~h}$ at $1300^{\circ} \mathrm{C}$ in a horizontal tube furnace with Pyrox ${ }^{\circledR}$ (HIMETAL, Traunstein, Germany) heating elements, and then cooled slowly for about $24 \mathrm{~h}$ (about $0.5-1 \mathrm{~K} \mathrm{~min}^{-1}$ ). This procedure avoids cracking caused by thermal stresses during cooling. The small axial load exerted on the rods and the sample insures a good

\section{Imaginary Component of Shear Viscosity}

LGM: $82 \%$ melt $+9 \%$ bubbles $+9 \%$ sapphire spheres

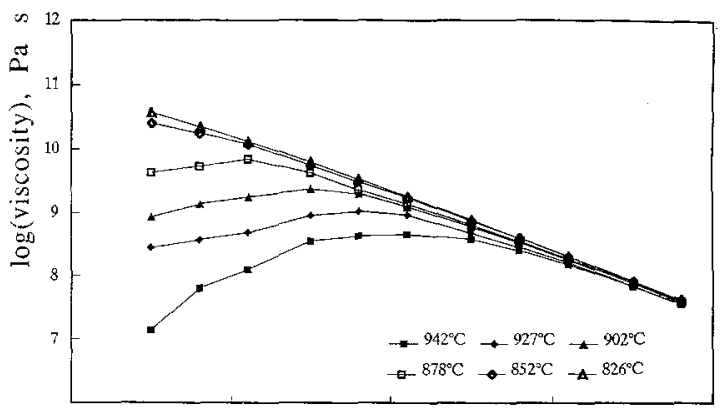

LGM: $68 \%$ melt $+16 \%$ bubbles $+16 \%$ sapphire spheres

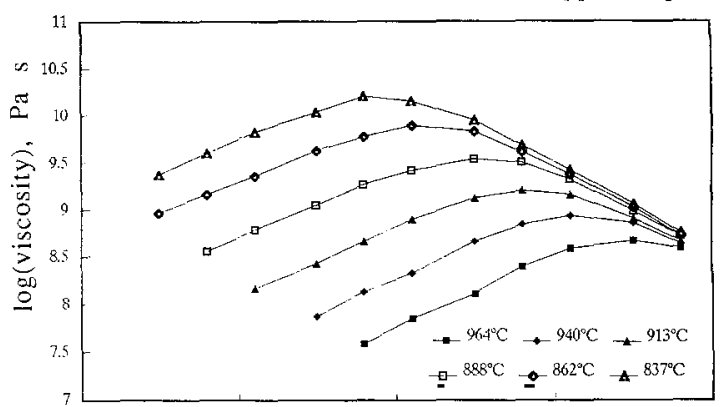

LGM: $20 \%$ melt $+40 \%$ bubbles $+40 \%$ sapphire spheres

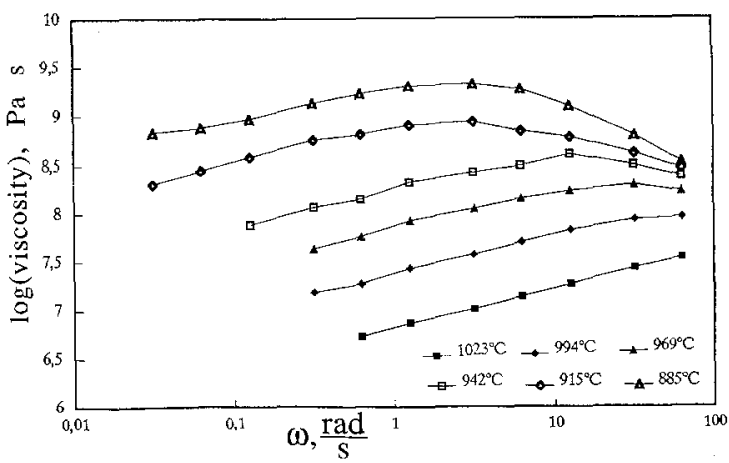

Fig. 2. The real and imaginary components of complex shear viscosity of rhyolite samples with crystals and bubbles. 
mechanical contact between "them. Finally, the foil was carefully removed from the sample and the entire assemblage of two rods and sample between them was installed in a torsion deformation device whose principle of operation and calibration procedure have been previously described (Bagdassarov and Dingwell, 1993a). Samples prepared using this procedure contained about equal volume percentages of crystals and bubbles, i.e. about $8 \%$ bubbles at $8 \%$ crystals, about $16 \%$ at $16 \%$, and about $40 \%$ at $40 \%$. Bubble-free samples containing $45 \%$ crystals and $55 \%$ melt were subsequently sintered in a vacuum furnace at $1300^{\circ} \mathrm{C}$ under $10^{-4}$ bar for $12 \mathrm{~h}$, and then fused to the alumina rods. Cross-sections of the samples charged with sapphire crystals (Figs. 1(a) and (b)) have been analyzed using a Tracor Northern (Middleton, WI, USA) TN-8500 ${ }^{\circledR}$ Image Analysis
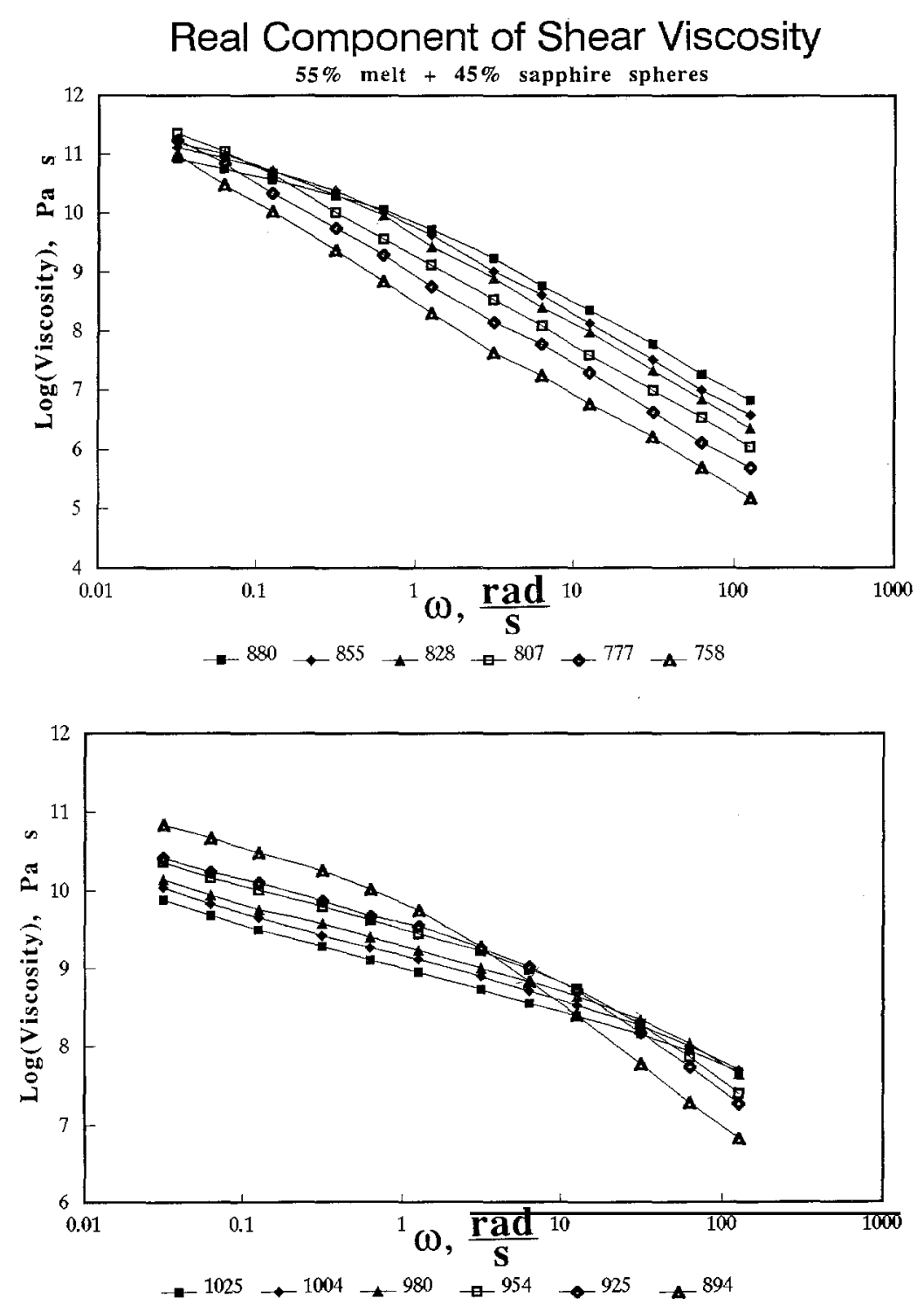

Fig. 3. The real component of shear viscosity of a sample containing $45 \%$ of crystals. 
System combined with an optical microscope to derive the volume percentages of bubbles, melt and crystals (Bagdassarov and Dingwell, 1992). Microprobe analysis (Camebax (CAMECA, Paris, France) microprobe, at $15 \mathrm{kV}$ and $15 \mathrm{nA}$, with a beam spot of about $2 \mu \mathrm{m}$ ) of samples demonstrated small variations, about $1.5-2.5 \mathrm{wt} \%$ in $\mathrm{Al}_{2} \mathrm{O}_{3}$ content in the rim of approximately $5 \mu \mathrm{m}$ width around sapphire spheres, and, practically, the absence of any significant variations in melt
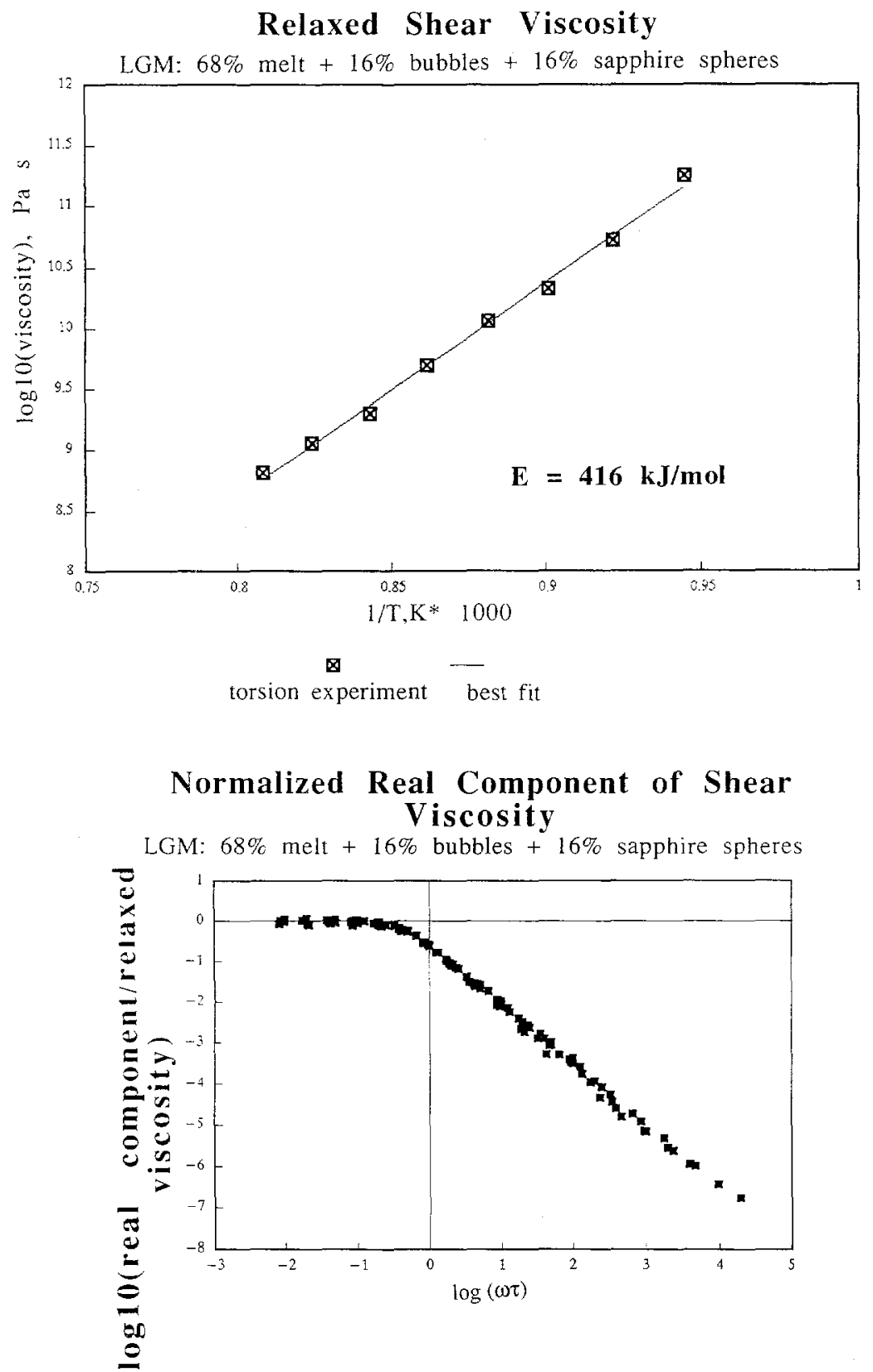

Fig. 4. (a) Relaxed shear viscosity as a function of temperature for a sample with crystal content below critical. (b) Normalized real component of shear viscosity as a function of $\log (\omega \tau)$. 
composition at distances greater than $20 \mu \mathrm{m}$ (see Table 1).

\section{Experimental results}

\subsection{Shear viscosity}

The torsion measurements have been carried out in the frequency range $0.005-20 \mathrm{~Hz}$ (with steps of $0.3 \log \mathrm{Hz}$ ) and temperature range $750-$ $1050^{\circ} \mathrm{C}$ (with steps of $25^{\circ} \mathrm{C}$ ). The measurements yield the absolute complex shear modulus $G^{*}(\omega)$ and phase shift $\varphi(\omega)$ between applied torque and resultant angular deformation for each temperature. From these data, the real $\left(G^{\prime}\right)$ and imaginary $\left(G^{\prime \prime}\right)$ components of shear modulus have been calculated by

$$
\begin{aligned}
& G^{\prime}(\omega)=G^{*}(\omega) \cos [\varphi(\omega)], \\
& G^{\prime \prime}(\omega)=G^{*}(\omega) \sin [\varphi(\omega)]
\end{aligned}
$$

\section{Imaginary Component of Shear Modulus}
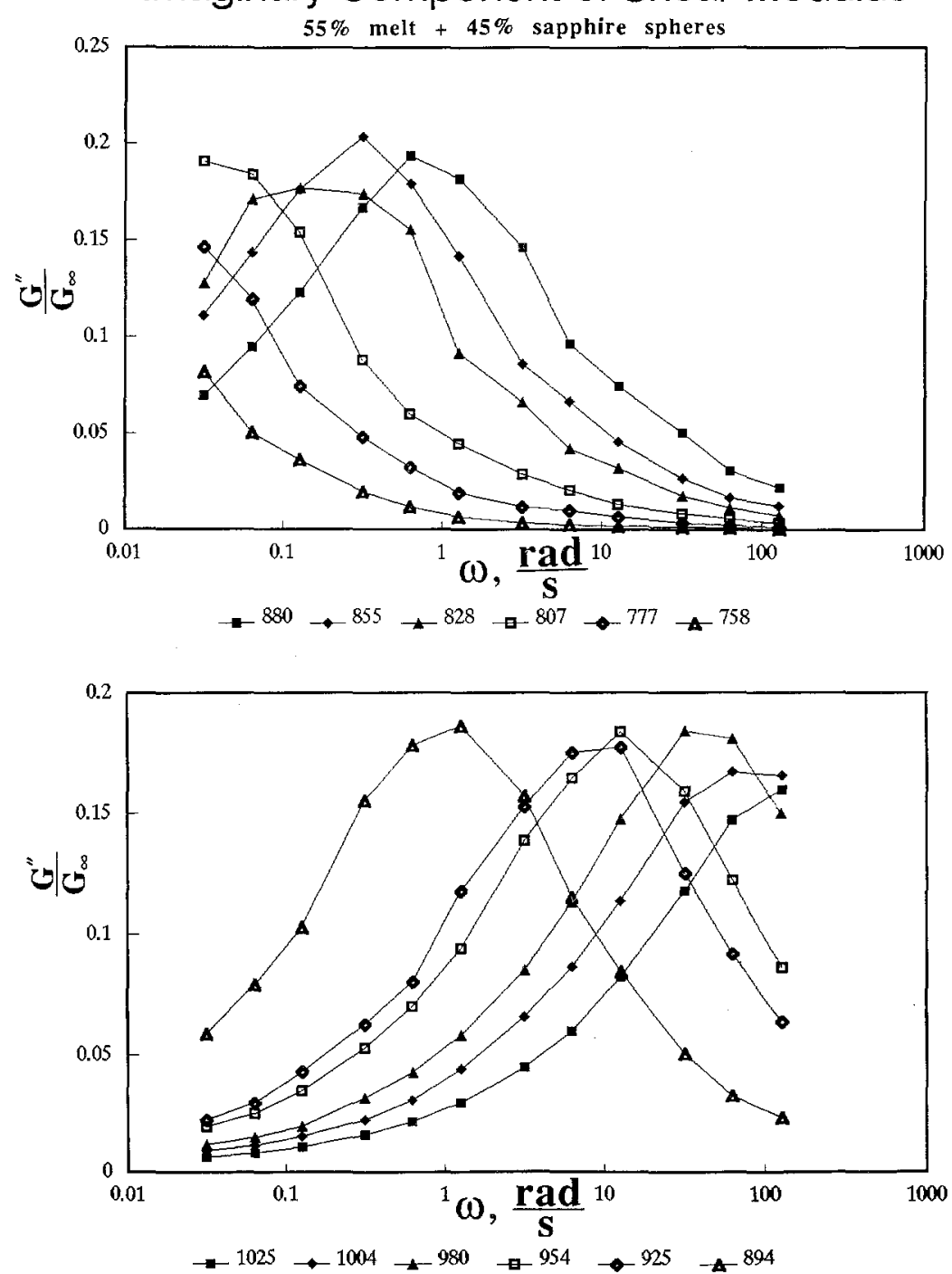

Fig. 5. The imaginary component of shear modulus of a rhyolite sample containing $45 \%$ of crystals. 
The frequency-dependent real and imaginary parts of shear viscosity can be calculated from $G^{\prime}$ and $G^{\prime \prime}$ using the expressions

$$
\eta^{\prime}(\omega)=G^{\prime \prime}(\omega) / \omega, \quad \eta(\omega)^{\prime \prime}=G^{\prime}(\omega) / \omega
$$

where $\omega=2 \pi f$ angular velocity (in $\mathrm{rad} \mathrm{s}^{-1}$ ), and $f$ is the oscillation frequency (in $\mathrm{Hz}$ ).

The experimental data for the real and imaginary components of shear viscosity are illustrated in Fig. 2. For samples containing bubbles and crystals it should be noted that, with decreasing frequency, the real component of the shear viscosity increases and reaches the relaxed (frequency-independent) Newtonian value $\eta(0)$. With the increase in concentration of rigid inclusions the relaxed value of the shear viscosity progressively ceases to exist (see Fig. 3). At high concentrations of crystals, the curves of $\log \left(\eta^{\prime}\right)$ vs. $\log (\omega)$ have a non-zero slope in the lowfrequency-high-temperature region and a frequency-independent viscosity is not observed. The values of relaxed shear viscosity obtained on sam- ples with crystal content of $40 \%$ vol. or less have been plotted as a function of $1 / T$ in Fig. 4. The Arrhenius dependence $\log \left(\eta_{\text {relaxed }}\right) \sim 1 / T$ on this graph indicates that inclusion-bearing rhyolite suspensions with $40 \%$ or less of crystals (non-deformable inclusions), as well as homogeneous rhyolite melts, are 'strong' liquids, i.e. those with 'self-reinforcing tetrahedral network structure' (Angell, 1991). The temperature dependence of viscosity of inclusion-bearing suspensions with a volume fraction of crystals below the critical value is still controlled by the rheology of the 'strong' interstitial melt which relates to a unique thermally activated process.

The temperature dependence of the relaxed shear viscosity is independent of concentration of rigid inclusions for less than $45 \%$ of crystals. The Arrhenius activation energy is $416 \pm 14 \mathrm{~kJ} \mathrm{~mol}^{-1}$. The presence of deformable bubbles and non-deformable sapphire crystals affects only the effective shear viscosity and unrelaxed shear modulus, not the activation energy of viscous flow. The clearly Arrhenian temperature dependence of the

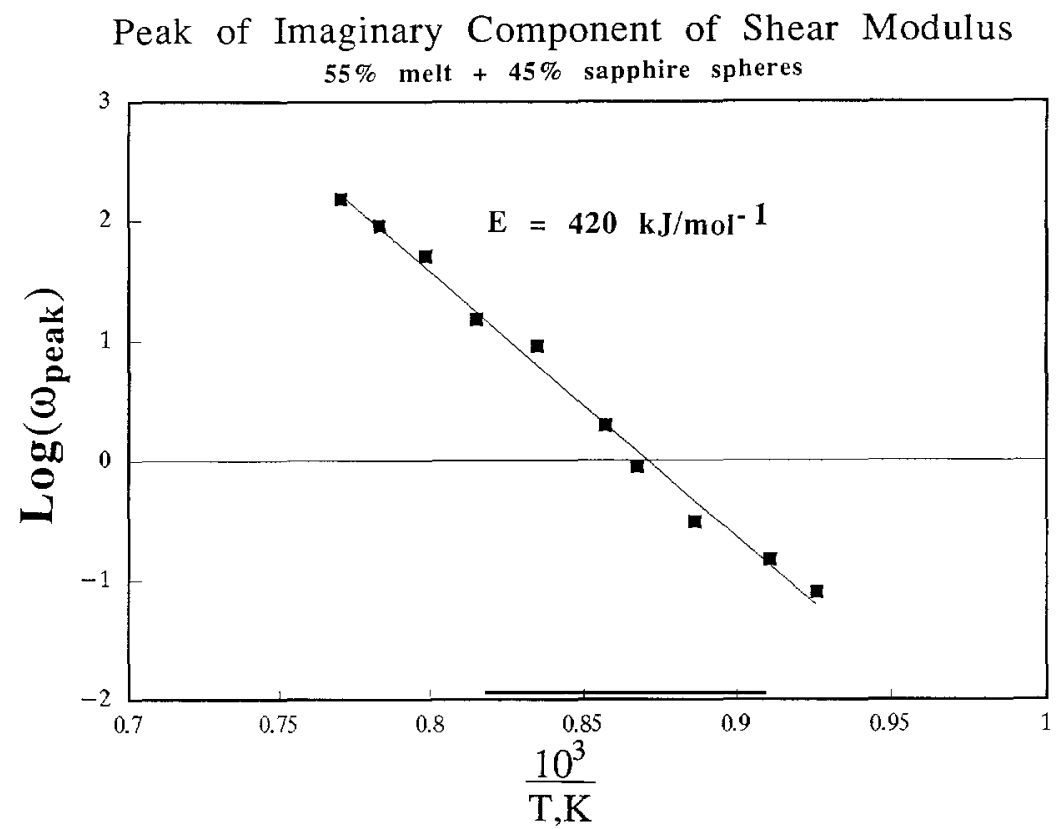

Fig. 6. The temperature dependence of peak frequency of the imaginary component of shear modulus in a rhyolite sample containing $45 \%$ of crystals. 
shear viscosity indicates a thermorheologically simple behavior of our samples in the temperature range of experiments (e.g. Brawer, 1985). This can be used to reduce the experimental data obtained at various frequencies and temperatures to master curves based on the dimensionless variable $\omega \tau$ (e.g. Bagdassarov and Dingwell, 1993a), where

$\tau \approx \tau_{0} \exp (E / R T)$

The real component of shear viscosity normalized to the relaxed shear viscosity at a given temperature can be plotted as a function of $\log \omega \tau$. The kink on the master curve which occurs at $\log (\omega \tau) \approx-0.5$ indicates the limit of Newtonian viscous behavior of this material (Fig. 4).

For the case of the sample containing $45 \%$ sapphire spheres and no bubbles in the intergranular space, a relaxed viscosity is never attained (Fig. 3). The activation energy in Eq. (6) for the dimensionless variable $\omega \tau$ can be derived from the temperature dependence of the peak in the imaginary component of the shear modulus (Fig. 5). Values of $\log \left(\omega_{\text {peak }}\right)$ plotted as a function of reciprocal absolute temperature exhibit an Arrhenius type of behavior, and the activation energy estimated from this plot is $420 \pm 15 \mathrm{~kJ} \mathrm{~mol}^{-1}$, the same as for rhyolite melt with bubbles or with bubbles and smaller concentrations of sapphire spheres (Fig. 6).

\subsection{Shear modulus}

The data for $G^{\prime}$ and $G^{\prime \prime}$ at various frequencies and temperatures have also been reduced to a master curve via the dimensionless variable $\omega \tau$ (Fig. 7). The difference in master curves for samples with different crystal concentrations lies in the asymmetry of the imaginary component of the shear modulus at low crystal concentrations and the symmetrical form of the master curve for samples with high crystal concentrations. The asymmetrical form of the master curve illustrates the stretched or $\beta$-exponential relaxation which has been observed for silicate melts (e.g. Brawer, 1985; Scherer, 1986) and for vesicular rhyolite melts (e.g. Bagdassarov and Dingwell, 1993a).
Complex Shear Modulus

LGM : $82 \%$ melt $+9 \%$ bubbles $+9 \%$ sapphire spheres

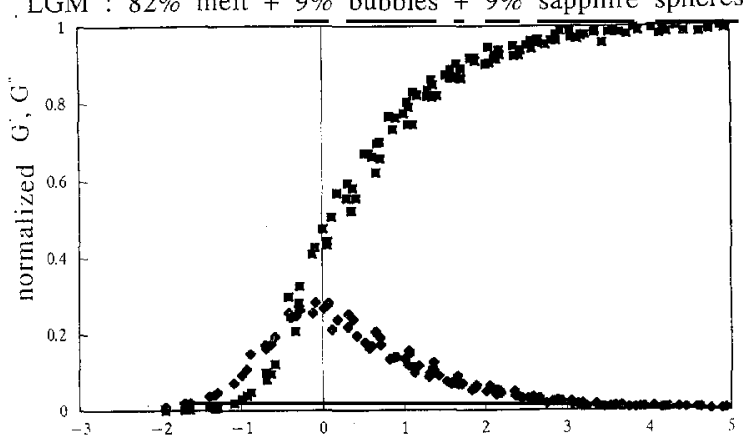

LGM : $68 \%$ melt $+16 \%$ bubbles $+16 \%$ sapphire spheres

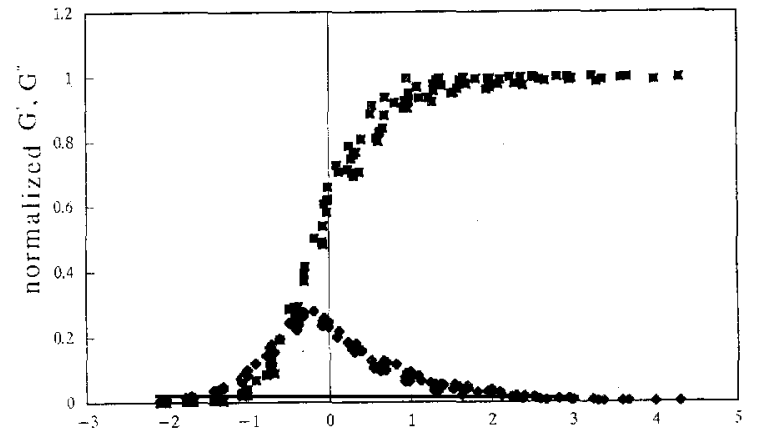

LGM : $20 \%$ melt $+40 \%$ bubbles $+40 \%$ sapphire spheres

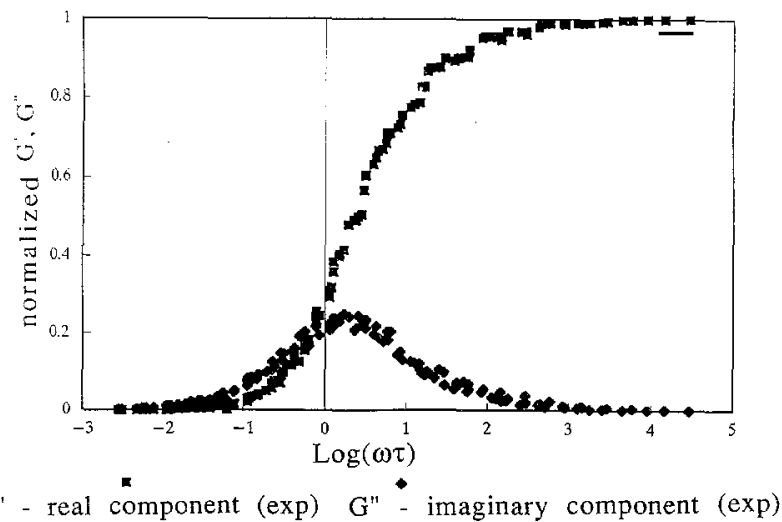

Fig. 7. The real and imaginary components of complex shear modulus as a function of $\log (\omega \tau)$.

The relative maximum of the imaginary component of shear modulus decreases with crystal concentration increase. The stress relaxation spectrum $H\left(\tau / \tau_{0}\right)$, to which the first approximation is the shape of the imaginary component of shear modulus (Philippoff, 1965), tends to a symmetri- 
cal form. The sample with $45 \%$ crystals and no bubbles exhibits growth in the component of shear stress relaxation spectrum at relaxation times slower than the main relaxation time (the structural relaxation of the melt). This slow relaxation mechanism relates to the relative movement of crystals and melt. Mechanical interaction between crystals results in a small non-zero elastic component of strain even at low strain-rates and high temperatures.

\subsection{Cole-Cole diagram}

The Cole-Cole diagram is another form of graphic presentation of dynamic experiment data using a complex plane of shear modulus in which the imaginary part of the complex shear modulus

\section{Cole-Cole Diagram}
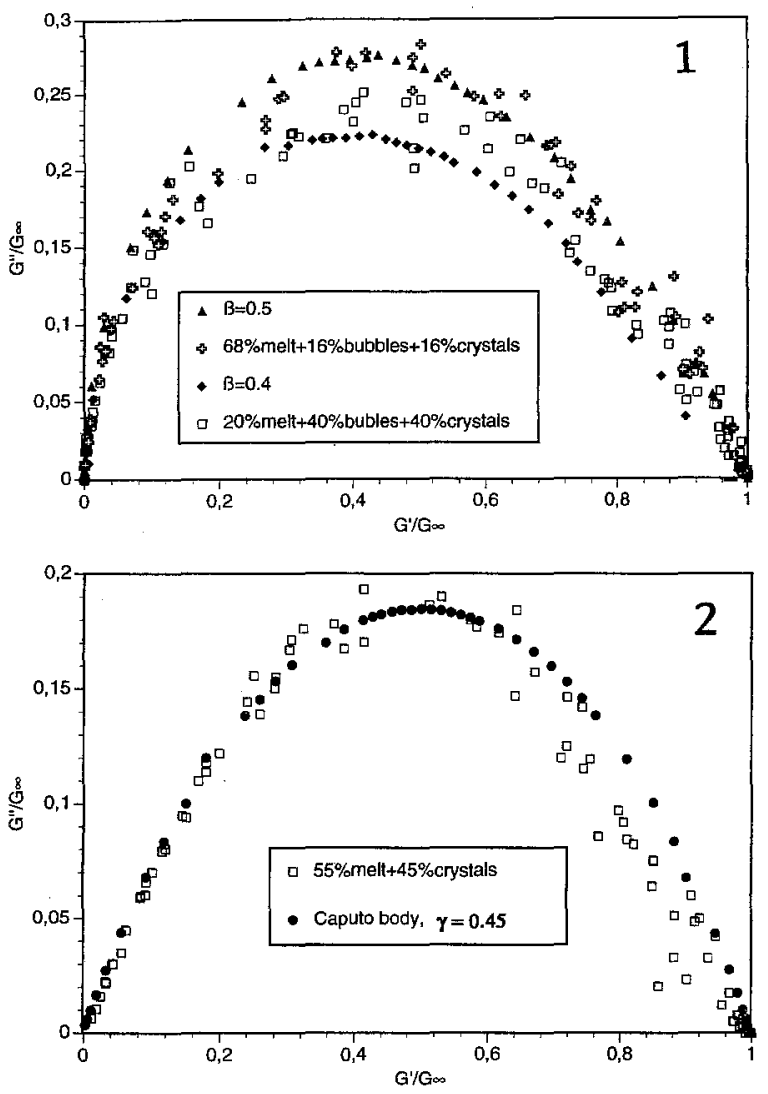

Fig. 8. A Cole-Cole diagram for the samples studied, (1) with bubbles and (2) without bubbles. is plotted against the real part, each point being characteristic of one $\omega \tau$ value (Cole and Cole, 1941). For a Maxwell liquid (a Debye type of relaxation) the Cole-Cole diagram is a semi-circle with radius $0.5 G_{\infty}$, the center of which is located on the $G^{\prime}$-axis. In the case of a $\beta$-relaxation (e.g. Brawer, 1985) the shape of the Cole-Cole diagram is a skewed arc intersecting the $G^{\prime}$-axis at some angle approximately $(\beta \pi / 2)$ at the $G^{\prime} / G_{\infty}$ $\rightarrow 1$ limit. In the case of anelastic solids (e.g. the Caputo body model, $Q$-power law body), the shape of the Cole-Cole diagram is a semi-circle with the locus lying below the $G^{\prime}$-axis.

The Cole-Cole diagram in Fig. 8 shows the difference between two samples, one possessing and one not possessing relaxed shear viscosity. The asymmetrical semicircle skewed along the $x$-axis towards the high-frequency-low-temperature range is typical for silicate melt behavior at high viscosities (e.g. Perez et al., 1981), and has been observed also for porous rhyolite samples (Bagdassarov and Dingwell, 1993a). The complex shear modulus for this type of behavior can be described as

$$
\begin{aligned}
& G^{*}(\omega \tau) \\
& \quad=\omega \tau \int_{0}^{\infty} \exp \left(-t^{\beta}\right)[\cos (\omega \tau t)+i \sin (\omega \tau t)] \mathrm{d} t .
\end{aligned}
$$

(Nowick and Berry, 1972). For rhyolite melt the parameter $\beta$ has been estimated to be about 0.5 and is independent of porosity (Bagdassarov and Dingwell, 1993a). For the inclusion-bearing rhyolite melt (68\% melt plus $16 \%$ bubbles plus $16 \%$ crystal) the shape of the Cole-Cole diagram is very close to the theoretical shape for the $\beta$-relaxation exponent with $\beta \approx 0.5$. With increasing crystal content (sample consisting of $20 \%$ melt plus $40 \%$ bubbles plus $40 \%$ crystals) $\beta$ decreases slightly to about 0.45 (Fig. 8(1)).

The bubble-free sample containing $45 \%$ crystals has a symmetrical Cole-Cole diagram which can be described as the Caputo body behavior of an anelastic solid:

$G^{*}(\omega \tau)=\frac{(i \omega \tau)^{\gamma}}{(i \omega \tau)^{\gamma}+1}$ 
(i.e. Körnig and Müller, 1989). The value of the parameter $\gamma$ estimated from Fig. 8(2) is about 0.45 . This means that the transition from the viscoelastic behavior of dilute suspensions to the solid-like behavior of concentrated suspensions is observable in the changing of the shape of a Cole-Cole diagram (broadening of the frequency range of dispersion, and smaller maximum value of the mechanical energy absorption). The weak interaction of rigid spheres at low frequencies results in a symmetrical Cole-Cole diagram similar to that for a Caputo body. The curve intersects the $G^{\prime}$-axis at an angle of about $45^{\circ}$. The transition from an asymmetrical to a symmetrical form of the imaginary component of the shear modulus is related to the growth of the elastic component of strain in the low-frequency-hightemperature region. This means that these concentrated suspensions must possess a very small but non-zero shear modulus even at low frequencies and high temperatures which we are unable to resolve in the torsion apparatus (this shear modulus is estimated to be $10^{7} \mathrm{~Pa}$ or less).

\subsection{Internal friction}

The viscoelastic behavior of materials is often expressed as the internal friction or the inverse of the mechanical quality factor $Q^{-1}(\omega)$,

$Q^{-1}(\omega)=G^{\prime \prime}(\omega) / G^{\prime}(\omega)=\tan [\varphi(\omega)]$

(e.g. Nowick and Berry, 1972). The present experimental results for $Q^{-1}$ measurements in rhyolite samples as a function of $\omega \tau$ are presented in Fig. 9. For all samples in the frequency-temperature range $\omega \tau>1, Q^{-1}(\omega \tau) \approx 1 /(\omega \tau)^{0.5-0.56}$. In the frequency range $\omega \tau<1$ and in samples with crystal concentrations less than $40 \%$, the slope of $\log \left(\mathrm{Q}^{-1}\right)$ as a function of $\log (\omega \tau)$ progressively decreases. The decrease of the parameter $\alpha$ in the relationship

$Q^{-1}(\omega \tau) \approx 1 /(\omega \tau)^{\alpha}$

with increasing inclusion content indicates a weaker internal friction of the material in comparison with a Maxwell viscoelastic liquid behavior. The observed behavior is more elastic than it should be in the case of a Maxwell element. The
Internal Friction

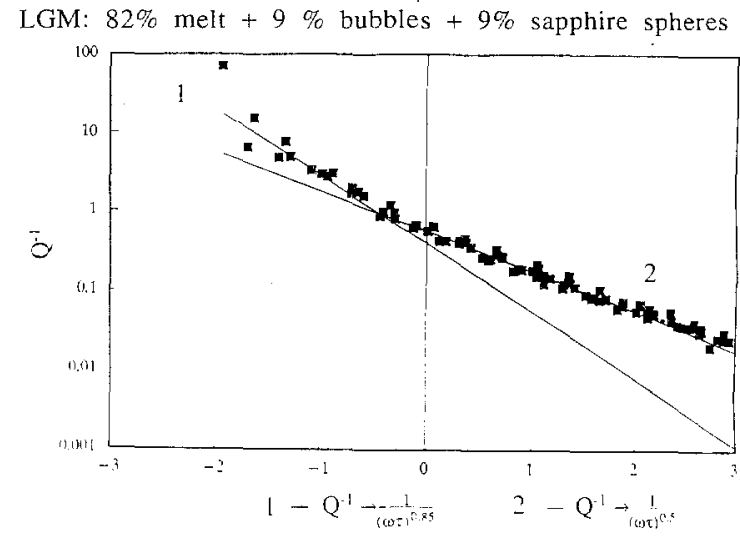

LGM: $68 \%$ melt $+16 \%$ bubbles $+16 \%$ sapphire spheres

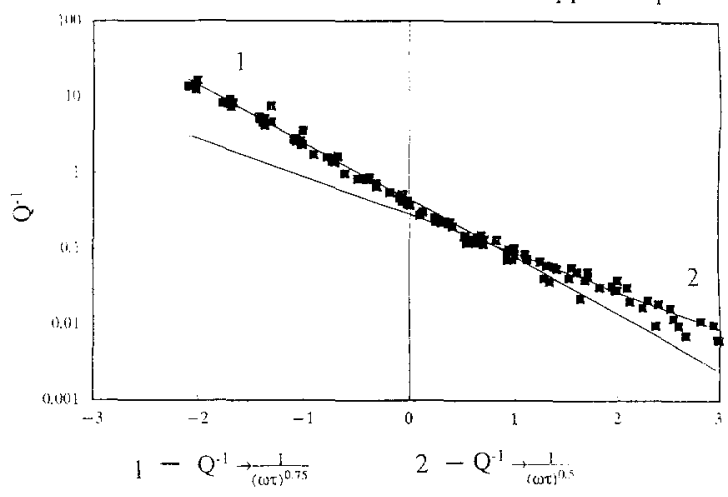

LGM: $20 \%$ melt $+40 \%$ bubbles $+40 \%$ sapphire spheres

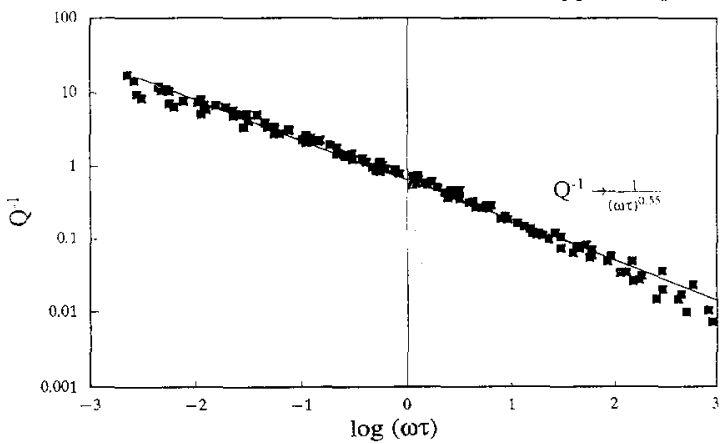

Fig. 9. Internal friction as a function of $\log (\omega \tau)$.

deviation from a Maxwell body model $\left(Q^{-1} \approx\right.$ $1 /(\omega \tau))$ in the range $\omega \tau>1$ is attributed to microscopic structural heterogeneities (a range of $Q_{n}$ species and/or bond strengths) in the melt (i.e. the extended spectrum of the shear stress relaxation commonly observed for silicate melts), 


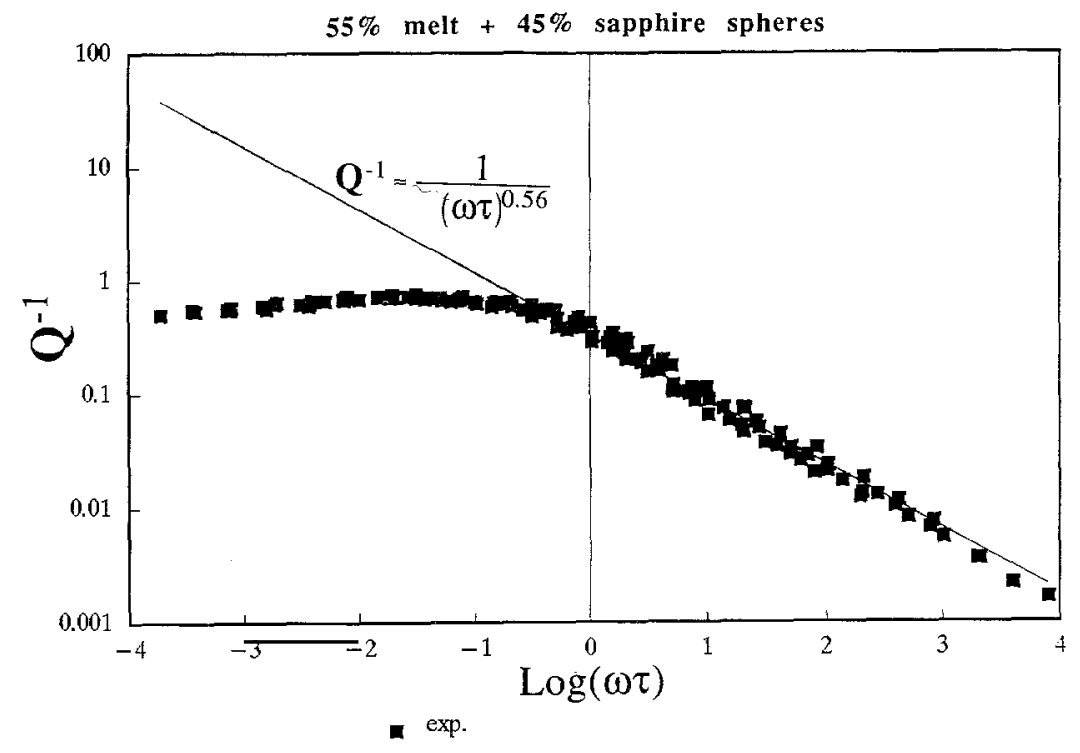

Fig. 9 (continued).

which has been also noted for vesicular rhyolite melts (Bagdassarov and Dingwell, 1993a).

For bubble-free melts in the frequency-temperature range $\omega \tau<1$ the dependence of $Q^{-1}$ on $\omega \tau$ is about $1 / \omega \tau$, i.e. that for a Maxwell liquid with a single relaxation time (Bagdassarov and Dingwell, 1993a). Thus the relaxation function at these temperatures and frequencies is nearly a Debye type. For the samples containing bubbles and crystals in the range of $\omega \tau<1$ the value of $\alpha$ in Eq. (10) is about 0.85 for the $8 \%$ porosity plus $8 \%$ of crystals, about 0.75 for the $16 \%$ porosity plus $16 \%$ of crystals, and about 0.55 for the $40 \%$ porosity plus $40 \%$ of crystals. This means that in the range $\omega \tau<1$ the relaxation is a non-Debye type relaxation for the rhyolite suspension, presumably because of interaction between deformable (bubbles) and rigid (crystals) inclusions. A similar effect of bubble content on the internal friction has been noticed in bubblebearing melts without crystals (Bagdassarov and Dingwell, 1993a). For the sample with $45 \%$ sapphire spheres, $Q^{-1}$ is independent of $\omega \tau$ at $\omega \tau<$ 1 . Thus, in general, the presence of these macroscopic heterogeneities makes the relaxation functions more stretched in the lower frequency range, and both the imaginary component of shear mod- ulus and the Cole-Cole diagram more symmetrical. The difference in asymptotic slopes $(-1$ and $-0.5)$ of $\log \left(Q^{-1}\right)$ vs. $\log (\omega \tau)$ in two extreme cases $(\omega \tau \rightarrow-\infty$ and $\omega \tau \rightarrow+\infty)$ demonstrates that at $\omega \tau>1$ the melt itself possesses more elasticity than the ideal viscoelastic Maxwell liquid. For the bubble- and crystal-bearing melt the anelastic contribution from the heterogeneities is significant at $\omega \tau<1$, resulting in less difference of the asymptotic slopes. The broader the size distribution of heterogeneities in the melt, the closer is the slope of $\log \left(Q^{-1}\right)$ vs. $\log (\omega \tau)$ to -0.5 at $\omega \tau<1$. At the critical percentage of melt, when rigid spheres begin to interact with each other, the behavior of the suspension becomes more like that of a solid, with an internal friction independent of frequency and temperature (the slope of $\log \left(Q^{-1}\right)$ vs. $\log (\omega \tau)$ is zero).

\section{Discussion}

The results obtained on complex shear viscosity, modulus and internal friction reveal the significant deviation of viscoelastic behavior of bubble plus crystal plus rhyolite melt suspensions from a Debye type of relaxation. The differences 
in viscoelasticity between pure rhyolite melt and viscous suspensions with concentrations of rigid spheres less than critical can be explained by a simple shift factor in the dimensionless variable $\omega \tau$ (or a change of effective relaxed viscosity). The trend in changes of relaxed shear viscosity and unrelaxed shear modulus as a function of crystal and bubble content is shown in Fig. 10. Deformable and non-deformable inclusions result in an opposite effect upon the relaxed viscosity and unrelaxed shear modulus. The shear strain in a suspension with deformable inclusions is con-

Effect of macroscale Heterogeneities on Shear $V$ iscosity

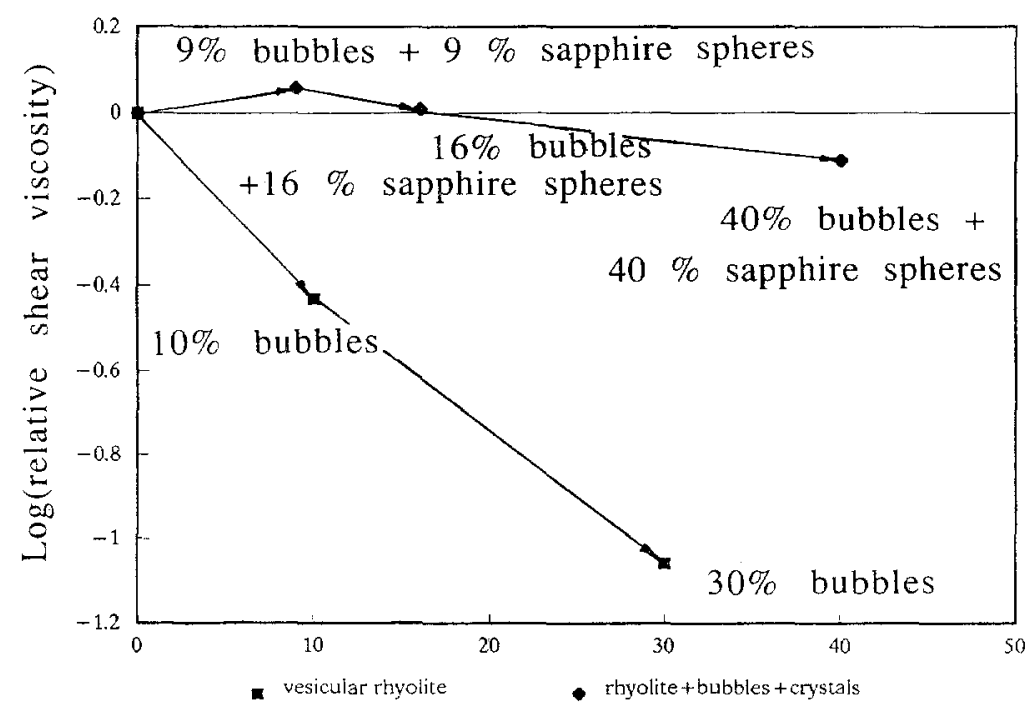

Effect of macroscale Heterogeneities on Shear Modulus

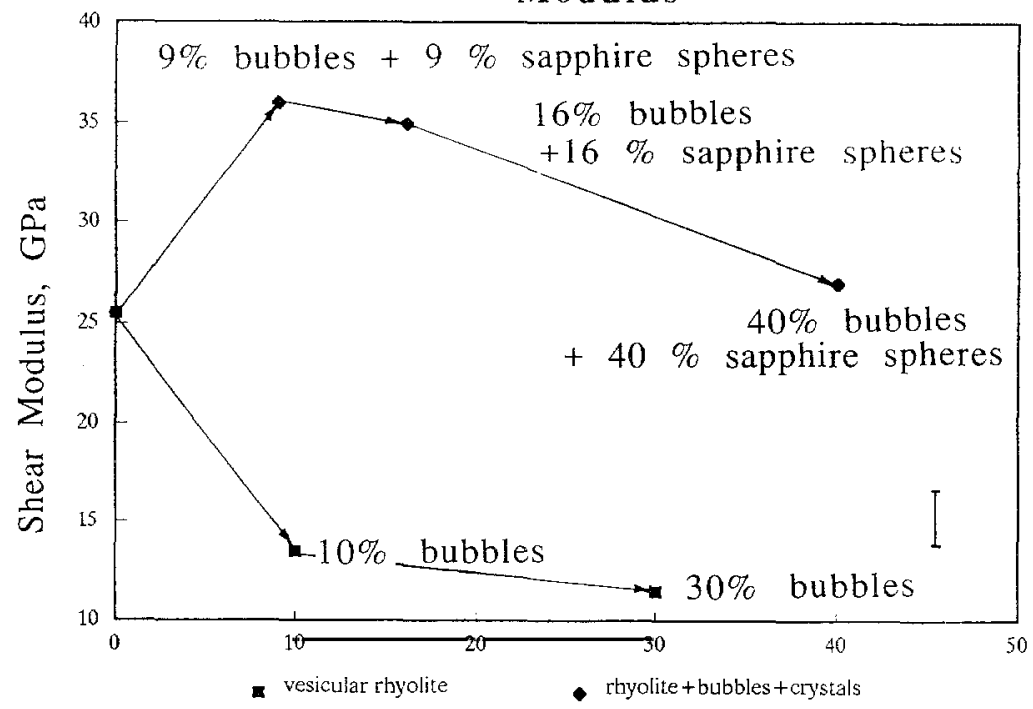

Fig. 10. Effect of macroscale heterogeneities on relaxed shear modulus and unrelaxed shear viscosity. 
centrated in the inclusions themselves, and thus the effective relaxed viscosity decreases with the content of bubbles. The presence of crystals results in concentration of shear strain in the surrounding melt, and the resulting shear flow resistivity (or relaxed viscosity) increases. The observed trend in unrelaxed shear modulus can be explained in the same way.

Crystals are non-deformable inclusions, thus their role in the rheology of shear flow is obvious: the relaxed shear viscosity (in the limit of moderate volume fraction of crystals) and unrelaxed shear modulus increase with the crystal content. Gas bubbles are not always deformable. The character of their deformation in a shear flow depends on the capillary number $(\mathrm{Ca})$ or relationship between the shear flow strain-rate and the characteristic time of bubble shape relaxation $\tau_{\mathrm{b}}$ (Bagdassarov and Dingwell, 1993a):

$\tau_{\mathrm{b}} \approx \eta R / \sigma$

where $\eta$ is the shear viscosity of the melt, $\sigma$ is the surface tension, and $R$ is the bubble radius. Thus, for small bubbles and low-viscosity melts the relaxed shear viscosity of the suspension increases with increase in bubble content, and vice versa for large bubbles and high-viscosity melts.

In general, magmatic suspensions can be divided in two classes: those which possess a relaxed shear viscosity and those which exhibit only strain-rate-dependent rheology. This difference in rheology depends on the volume fraction of crystals (rigid inclusions). For a melt without vesicles this critical volume fraction is less than $45 \%$ of crystals. If the melt contain bubbles in the intercrystalline space, this critical concentration can be higher, because bubbles, being deformable under low shear strain-rate, can significantly decrease the effective viscosity of the material. Thus, the suspension containing $40 \%$ crystals plus $40 \%$ bubbles has a very weak solid-like behavior. With increasing proportion of crystals the solid-like behavior results in non-zero shear modulus at low frequency. The mechanical interaction of crystals via viscous melt leads to a yicld strength in concentrated magmatic suspensions. This has also been observed in laboratory experiments on magmatic melts (Ryerson et al., 1988) and in field observations of lava flows (e.g. Pinkerton and Sparks, 1978; Pinkerton and Stevenson, 1992).

In the light these new data, it is clear why the application of Roscoe or Einstein-Roscoe expressions for predicting the rheology of magmatic suspension with concentrations of crystals of more than $30-40 \%$ fails. Such suspensions do not possess a Newtonian strain-independent viscosity. Rather their behavior is a transient one having features of solid-like behavior (e.g. a yield strength).

Magma or lava flows will change their style of viscoelastic behavior progressively with degassing and bubble-bursting processes (when sufficiently strained large bubbles change their size by dividing into a number of small ones). In a situation when a magma is ascending to the surface through a magmatic channel, or when a lava flow is moving on the slope of a volcano, the creep model of magma rheology has to be applied when the volume fraction of crystals is more than about $40 \%$ (without bubbles). The flow of magma in this situation will have a developed plug-like velocity profile, as a result of yield stress. The shear stress in viscous flow is a maximum near a rigid stationary boundary. As a result of non-Newtonian rheology, the shear flow (velocity gradient) will develop in zones with high shear stresses, and the interior of the flow moves as a unit without internal shear (Williams and McBirney, 1979).

The vesiculation process of felsic magma may be intensive at the stage either when the pressure decreases below the vapor saturation value or when the crystallization of anhydrous phases starts (Candela, 1991). As has been shown experimentally (Bagdassarov and Dingwell, 1993b), in the second case, vapor bubbles nucleate heterogeneously and fast. At the stage of nucleation, the small size of freshly nucleated bubbles may result in a temporary effective viscosity increase. Later, however, at the stage of diffusional bubble growth, when $\tau_{\mathrm{b}}$ is appreciable owing to the increase in the mean bubble size, the vesiculation of magma results in a decrease of the effective viscosity at the low strain-rates $10^{-6}-10^{-5} \mathrm{~s}^{-1}$ (Bagdassarov and Dingwell, 1992) which are relevant for effusive eruptions such as the Mount St. Helens dome-building phase. This resurgent boil- 
ing vesiculation near the wall of a magma channel may accelerate the flow as a result of the lubrication effect. The vesiculation results also in a transition to Newtonian rheology and in the development of a parabolic velocity profile of the shear flow. Thus, vesiculation on the wall of magma conduits may effectively reduce the jamming effect of partially crystalline magma. This suggested mechanism possibly occurs during the growth of highly viscous magma domes of silicic composition (Mount St. Helens, for example, before the paroxysmal phase described). The slow growth of the domes is often associated with permanent fumarolic activity located around the periphery of the vent (e.g. Tazieff, 1982), which may indicate on the location of the zone of vapor bubble vesiculation (Wohletz and Heiken, 1992).

A similar mechanism has been suggested for the development of textures in obsidian flows and domes (Fink and Manley, 1987), and the potentially decisive role of a low-viscosity vesicular boundary layer (vesicular lubrication) between the magmatic column and the conduit walls in the triggering of flow is evident in the light of the experimental data obtained.

\section{Conclusions}

The present study of shear viscosity of rhyolite melts with various amounts of crystals and bubbles has shown the following:

(1) two different viscoelastic behaviors have been distinguished. The melt had the dominant effect on viscoelasticity below a critical concentration of crystals $(\phi<45 \%)$, and weak elastic behavior was caused by mechanical interaction between crystals at or below a critical concentration of melt.

(2) The relaxed shear viscosity of crystalbearing rhyolite melt increases with volume fraction of crystals. At a critical concentration of crystals, however, a relaxed viscosity is never observed, even at low frequencies and high temperatures. The shear modulus is then non-zero at low frequencies and high temperatures. The activation energy of viscous flow in rhyolite melt and in melt with crystals remains unchanged (about
$416 \pm 14 \mathrm{~kJ} \mathrm{~mol}^{-1}$ ) and corresponds to the activation energy of the peak in the imaginary component of shear modulus with a critical concentration of crystals (about $420 \mathrm{~kJ} \mathrm{~mol}^{-1}$ ).

(3) The internal friction $Q^{-1}$ plotted on a double-log plot against the dimensionless variable $\omega \tau$ has different slopes above and below $\omega \tau=1$. At $\omega \tau>1$, the slope $Q^{-1}$ vs. $\omega \tau$ on a double-log scale is about -0.5 and is independent of crystal concentration. Above the critical percentage of crystals, $Q^{-1}$ is independent of $\omega \tau$ on the lowfrequency-high-temperature range.

(4) The relaxation spectrum of shear stresses exhibits a more symmetrical distribution as the volume concentration of crystals increases. The shift of the main relaxation time $\tau_{0}$, around which the distribution of relaxation times is centered, with respect to the Maxwell relaxation time of the melt depends on the volume fraction of crystals and bubbles.

(5) The shape of the Cole-Cole diagrams changes with the increase of crystal content. In rhyolite melt below the critical concentration of rigid inclusions the shape is asymmetrical and related to a $\beta$-relaxation law of shear stresses with $\beta \approx 0.5$. At a critical concentration of inclusions when the mechanical contacts between crystals determine the elastic behavior of the suspension, the Cole-Cole diagram is symmetrical, and is described by a Caputo body stress relaxation function with $\gamma \approx 0.45$.

(6) The present work, in combination with previous studies (Bagdassarov and Dingwell, 1992; 1993a,b), illustrates that magma can possess either a relaxed shear viscosity or a yield strength, and can be effectively non-Newtonian depending on the relative proportion of crystals and vesicles in the melt. The vesiculation of magma during subvolcanic flow may permit the viscous flow of otherwise Bingham or viscoplastic crystal-rich magmas.

\section{Acknowledgements}

This work was supported by Research Grant EV5-CT92-0178 of the European Community Council and by the Alexander von Humboldt 
Foundation. The authors are grateful to Professor J. Fink (Arizona State University, Tempe) for the sample of Little Glass Mountain obsidian, to Professor $\mathrm{H}$. Berckhemer for discussions, $\mathrm{K}$. Klasinski for development of electronic equipment, $\mathrm{H}$. Schulze for the sample preparation, and G. Hermannsdörfer for the technical assistance. The comments of two anonymous reviewers have significantly improved the manuscript.

\section{References}

Angell, C.A., 1991. Relaxation in liquids, polymers and plastic crystals - strong/fragile patterns and problems. J. NonCryst. Solids, 131-133: 13-31.

Arzi, A.A., 1978. Critical phenomena in the rheology of partially melted rocks. Tectonophysics, 44: 173-184.

Bagdassarov, N.S. and Dingwell, D.B., 1992. Rheological investigation of vesicular rhyolite. J. Volcanol. Geothermal Res., 50: 307-322.

Bagdassarov, N.S. and Dingwell, D.B., 1993a. Frequency dependent rheology of vesicular rhyolite. J. Geophys. Res., 98: 6477-6487.

Bagdassarov, N.S. and Dingwell, D.B., 1993b. Deformation of foamed rhyolite under internal and external stresses: an experimental investigation. Bull. Volcanol., 55: 147-154.

Berckhemer, H., Kampfmann, W. and Aulbach, E., 1982. Anelasticity and elasticity of mantle rocks near partial melting. In: W. Schreyer (Editor), High-Pressure Researches in Geosciences. Schwartzerbart'sche Verlagsbuchhandlung, Stuttgart, pp. 113-132.

Brawer, S., 1985. Relaxation in Viscous Liquids and Glasses. American Ceramical Society, Columbus, OH, 220 pp.

Candela, P.A., 1991. Physics of aqueous phase evolution in plutonic environments. Am. Mineral., 76: 1081-1091.

Chen, H.-S. and Acrivos, A., 1978. The effective elastic moduli of composite materials containing spherical inclusions at non-dilute concentrations. Int. J. Solids Struct., 14: 349-364.

Cole, K.S. and Cole, R.H., 1941. Dispersion and absorption in dielectrics. J. Chem. Phys., 9: 341-351.

Dingwell, D.B., Bagdassarov, N.S., Bussod, J. and Webb, S.L., 1993. Magma rheology. In: R.W. Luth (Editor), Short Course Handbook on Experiments at High Pressure and Applications to the Earth's Mantle, Vol. 21. Mineralogical Association of Canada, Edmonton, Alta, Canada, pp. 131196.

Fink, J.H. and Manley, C.R., 1987. Origin of pumiceous and glassy textures in rhyolite flows and domes. Geol. Soc. Am. Spec. Pap., 212: 77-78.

Kanai, H., Navarette, R.C., Macosko, C.W. and Scriven, L.E., 1992. Fragile network and rheology of concentrated suspensions. Rheol. Acta, 31: 333-334.
Körnig, M. and Müller, G., 1989. Rheological models and interpretation of postglacial uplift. Geophys. J. Int., 28 (4): 243-253.

Matsumoto, T., Segawa, Y., Warashina, Y. and Onogi, S., 1973. Non-linear behavior of viscoelastic materials. II. The method of analysis and temperature dependence of nonlinear viscoelastic functions. Trans. Soc. Rheol., 17: 47-62.

Michaels, A.S. and Bolger, J.C., 1962. The plastic flow behavior of flocculated kaolin suspensions. I EC Fundam., 1: $153-162$.

Nguyen, Q.D. and Boger, D.V., 1992. Measuring the flow properties of yield stress fluids. Annu. Rev. Fluid Mech., 24: $47-88$.

Nowick, A.S. and Berry, B.S., 1972. Anelastic Relaxation of Crystalline Solids. Academic Press, New York, 667 pp.

Onogi, S., Masuda, T. and Matsumoto, T., 1970. Non-linear behavior of viscoelastic materials. I. Disperse systems of polystyrene solutions and carbon black. Trans. Soc. Rheol., 14: $275-294$.

Perez, J., Duperray, B. and Lefevre, D., 1981. Viscoelastic behaviour of an oxide glass near the glass transition temperature. J. Non-Cryst. Solids, 44: 113-135.

Philippoff, W., 1965. Relaxation in polymer solutions, liquids, and gels. In: W.P. Mason (Editor), Physical Acoustics. Principles and Methods, Vol. 2, Part B, Academic, San Diego, CA, pp. 1-90.

Pinkerton, H. and Sparks, R.S.J., 1978. Field measurements of the rheology of lava. Nature, 276: 383-384.

Pinkerton, H. and Stevenson, R.J., 1992. Methods of determining the rheological properties of magmas at sub-liquidus temperatures. J. Volcanol. Geothermal Res., 53: 4766.

Roscoe, R., 1952. The viscosity of suspensions of rigid spheres. Br. J. Appl. Phys., 3: 267-269.

Roscoe, R., 1953. Flow properties of disperse systems. In: J.J. Hermans (Editor), Interscience, New York, Chapter 1.

Ryerson, F.J., Weed, H.C. and Piwinski, A.J., 1988. Rheology of subliquidus magmas. 1. Picritic compositions. J. Geophys. Res., 93: 3421-3436.

Scherer, G.W., 1986. Relaxation in Glass and Composites. Wiley-Interscience, New York, 331 pp.

Stein, D.J. and Spera, F., J., 1992. Rheology and microstructure of magmatic emulsions: theory and experiments, J. Volcanol. Geothermal Res., 49 (3-4): 157-174.

Tazieff, H., 1982. Dômes de magmas et dômes de lavas. C.R. Acad. Sci. Paris, Ser. II, 294: 151-153.

Webb, S.L., 1992. Low-frequency shear and structural relaxation in rhyolite melt. Phys. Chem. Minerals, 19: 240-245.

Williams, H. and McBirney, A.R., 1979. Volcanology. Freeman, Cooper, San Francisco, pp. 25-26.

Wohletz, K. and Heiken, G., 1992. Volcanology and Geothermal Research. University of California Press, Berkeley, pp. 177-223.

Zosel, A., 1982. Rheological properties of disperse systems at low stresses. Rheol. Acta, 21: 72-80. 